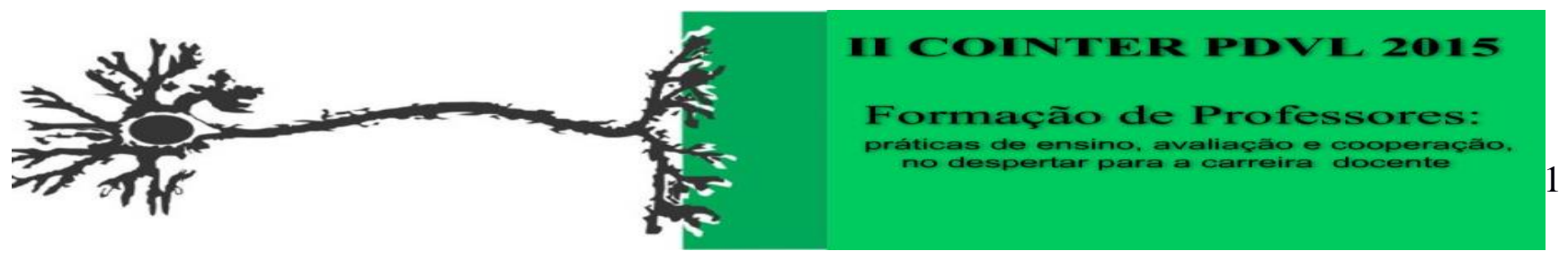

\title{
LABORATÓRIO DE AVALIAÇÃO: ELABORAÇÃO E TESTAGEM DE PROCESSOS E INSTRUMENTOS AVALIATIVOS A PARTIR DA PERSPECTIVA DA AVALIAÇÃO DA EXPERIÊNCIA
}

\author{
Apresentação: Comunicação Oral \\ Ana Maria da Cunha Rego ${ }^{1}$; Natália de Pontes Leite Monte ${ }^{2}$; Cintia de Abreu Arruda ${ }^{3}$; Maria \\ Tatiana da Silva Santos ${ }^{4}$; Kilma da Silva Lima Viana ${ }^{5}$
}

\begin{abstract}
Resumo
Este artigo tem o objetivo de apresentar uma proposta elaborada pela pesquisadora Viana acerca da materialização de práticas inovadoras de avaliação, denominada por ela de Laboratório de Avaliação. Considera-se de suma importância a busca por aproximar a teoria, o discurso e a prática de forma planejada. A proposta tem a perspectiva de construir um espaço de discussão, elaboração e testagem de instrumentos e processos avaliativos. Serão foco desse laboratório as práticas experimentais, os jogos didáticos e os instrumentos avaliativos de larga escala. Ressalta-se que desde 2010 foi iniciado o Grupo de Estudos e Pesquisas em Ensino de Ciências - GEPEC, sob a liderança de Viana, tendo como uma das linhas a Avaliação da Aprendizagem. Assim, tem sido formado grupos de estudantes que sistematicamente estuda as novas perspectivas da avaliação. A partir do início de 2016 os estudantes que são membros do GEPEC passaram por formação sistemática acerca da Avaliação da Experiência, que é o aporte teórico que fundamentará as ações do Laboratório de Avaliação.
\end{abstract}

Palavras-Chave: Laboratório, Avaliação da Experiência, Ensino de Ciências, Formação de Professores, Despertando Vocações.

\section{Introdução}

O campo da avaliação da aprendizagem apresenta diversas limitações, especialmente quando se trata de avaliação na área das Ciências da Natureza (Física e Química), que, historicamente, apresenta uma perspectiva de avaliação que está relacionada à abordagem tradicional do processo (LIMA, 2008). Pesquisas indicam que no cotidiano das instituições de educação é possível observar o quanto professores e estudantes vivenciam práticas avaliativas que, muitas vezes, não concordam, mas que parece não conseguir fazer diferente (VIANA, 2014).

Segundo Barros Filho (2002), a área de avaliação é uma das áreas mais regulamentadas na escola, mas se mostra como uma das que mais apresentam ambiguidades, pelo fato do grande distanciamento entre o que os documentos oficiais orientam, o discurso do professor e o que se

\footnotetext{
${ }^{1}$ Especialização em Docência do Ensino Superior, Estácio, anacunha11@hotmail.com

${ }^{2}$ Graduação em Pedagogia, FACOL, monteingles@hotmail.com

${ }^{3}$ Graduação em Licenciatura em Química, cintiaarruda@outlook.com

${ }^{4}$ Graduação em Licenciatura em Química, mariatatiana015@hotmail.com

${ }^{5}$ Doutora em Ensino de Ciências (Física e Química), Professora do IFPE, kilma.viana@vitoria.ifpe.edu.br
} 
vivencia em sala de aula. Com relação ao discurso do professor, ocorre que muitos apresentam discursos inovadores, porém a prática permanece estática, baseada em uma avaliação que prima pela memorização e reprodução do conhecimento.

Quando se observa a literatura acerca da avaliação, é perceptível que muitas propostas ainda estão apenas em letras numa folha de papel. A cada ano são lançados diversos livros, muitos estudiosos na área consagrados defendem uma perspectiva de avaliação, mas não veem materializadas.

Diante disso, o presente artigo tem por objetivo apresentar uma proposta inovadora no campo da avaliação, aqui denominada de Laboratório de Avaliação. Nossa proposta está fundamentada no aporte teórico da Avaliação da Experiência de Viana (2014). Nossos estudos serão fomentados a partir do Grupo de Estudos e Pesquisas em Ensino de Ciências - GEPEC e as ações serão postas em prática no âmbito do Programa Internacional Despertando Vocações para Licenciaturas - PDVL. Espera-se, a partir dessa proposta contribuir de forma significativa para a materialização de propostas inovadoras de avaliação no chão da escola.

\section{Fundamentação Teórica - Avaliação da Experiência}

De acordo com Viana (2014), o distanciamento entre as teorias da aprendizagem e da Avaliação é um dos principais problemas do ensino. Em suas pesquisas, observou que esse distanciamento é ainda maior no ensino e avaliação de Física e Química (LIMA, 2008; VIANA 2014), pois muitas vezes os professores já superaram metodologias mais tradicionais de ensino, mas não conseguem inovar no processo avaliativo, mantendo suas práticas avaliativas "com fortes aspectos excludentes, com viés autoritário, com o intuito de classificar e comparar o rendimento dos estudantes" (VIANA, 2014, p.16), além da forte ênfase de exercícios meramente quantitativos, a chamada matematização das Ciências da Natureza (VIANA, 2014). Outra crítica de Viana é a tentativa de nivelamento dos estudantes, quando se tenta a todo custo padronizar comportamentos e conhecimentos que desenvolveram ao longo de suas vidas de formas diversas. Diante disso, o Alternativismo Construtivo (KELLY, 1955) é o posicionamento assumido por Viana (2014), que afirma que cada pessoa constrói e interpreta o mundo de maneira única, porque é diretamente relacionado as experiências vividas anteriores.

Assim, Viana defende uma nova perspectiva de Avaliação, denominada por ela de Avaliação da Experiência, quando assume esse posicionamento filosófico e considera que a aprendizagem é uma Experiência, composta por cinto etapas (KELLY, 1955), tendo como fio condutor a avaliação a partir de um processo de reflexão.

Essa nova perspectiva da Avaliação da Experiência também é composta por cinco etapas em 
seu percurso metodológico e apresenta 3 (três) pressupostos e 8 (oito) princípios que estão de acordo com as ideias mais emergentes de ensino e de avaliação.

\section{Pressupostos:}

\section{Avaliação como parte fundamental do processo de ensino e aprendizagem.}

A literatura aponta que as práticas avaliativas, especialmente nas Ciências da Natureza (Física e Química) acontecem em momentos distinto do processo de ensino e não tem como objetivo a aprendizagem, mas, sim, a verificação da "capacidade" do estudante em reproduzir o que foi ensinado pelo professor (VIANA, 2008). Assim, esse pressuposto vai de encontro a essa ideia, pois concebe a avaliação como parte, não apenas integrante, mas também fundamental do processo tanto de ensino, quanto de aprendizagem.

\section{Caráter mutável das concepções.}

Para Viana (2014, p. 176), “as concepções são mutáveis, passíveis de revisões” e ressalta a grande importância dessa revisão. Viana (2014) busca, através de seus estudos, construir uma cultura de avaliação que supere a ideia de medo e de prestação de contas, tão comum no cotidiano das salas de aula, pois essa prestação de contas apenas reforça a ideia de que avaliar é reproduzir, quando deveria ser um momento rico de reconstrução e reflexão acerca do processo.

\section{Avaliação como instrumento de transformação.}

Mais uma vez, Viana coloca a avaliação em lugar de destaque, quando supera a perspectiva estática da avaliação. Dialogando com Kelly (1955) em relação às questões da aprendizagem, Viana (2014) afirma que essa transformação acontece nas cinco etapas do ciclo de construção da Avaliação da Experiência (Antecipação, Investimento, Encontro, Confirmação ou Desconfirmação e Revisão Construtiva). Dessa forma, na primeira etapa (Antecipação), o professor, a partir de uma avaliação diagnóstica, antecipa os conteúdos que precisarão ser abordados nas aulas. Da mesma forma, os estudantes, diante dessa avaliação, poderão antecipar o conhecimento "novo" que irão encontrar no percurso. Esse é momento em que professor e estudantes iniciam o diálogo e deve ser priorizada a escuta e o acolhimento de ideias. Na segunda etapa (Investimento), tanto professor, quanto os estudantes são engajados em momentos de estudos, aprofundamentos e debates, com o objetivo de se prepararem para a terceira etapa (Encontro). É nessa etapa que o "novo" é apresentado, discutido, resignificado. Coletivamente, os estudantes deverão testar suas hipóteses iniciais e o professor, a 
partir de aplicação de instrumentos avaliativos, dos mais variados, deverá auxiliar os estudantes nas novas descobertas. Observa-se aqui, o quanto essa perspectiva de avaliação está a serviço da aprendizagem. São os instrumentos avaliativos que indicarão o caminho que os estudantes estão seguindo e aquele que deverá seguir. Os seus resultados são pistas para a reorientação dos passos. Inclusive dos passos que o professor também trilhou até então. Esse momento conduz à quarta etapa (Confirmação ou Desconfirmação), pois a testagem das hipóteses fará com que os estudantes possam confirmar ou Desconfirmar suas hipóteses iniciais, que foram construídas durante as etapas da antecipação e do investimento. Finalmente, a quinta etapa (Revisão Construtiva). Essa etapa é de suma importância no processo avaliativo, pois é quando tanto o professor quanto os estudantes, diante do que foi vivenciado, realiza a autoavaliação, refletindo sobre todo o processo de construção. Deve ser um momento rico de interação e o processo também auxiliará os estudantes nessa revisão. Ao mesmo tempo, ele precisa estar aberto também às reconstruções, inclusive propostas pelos estudantes.

\section{Princípios}

\section{Princípio da Negociação.}

Para Viana (2014), o diálogo e a relação horizontal entre professor e estudantes é essencial para que a construção seja efetiva, assim, Viana defende como um dos princípios da Avaliação da Experiência a Negociação, que pressupõe busca por consensos (GUBA; LINCOLN, 1989). Ressalta ainda que a negociação deve estar presente nas decisões acerca do processo, como quais os instrumentos a serem utilizados, de que forma, porque. É sabido que a cultura da avaliação atual não conseguiu formar estudantes maduros para esse momento, mas Viana defende que é preciso começar. Se no início as decisões compartilhadas serão feitas de forma mais tímida, com o passar do tempo, será possível a vivência efetiva de práticas negociadoras maduras e coerentes.

\section{Princípio do Acolhimento.}

Essencial para que seja possível o consenso, pois é preciso o acolhimento à opinião do outro. Segundo Viana (2014, p. 179) "o dinamismo do consenso conduz a momentos de conflitos" e o acolhimento assegura que pessoas "de posições diferentes, divergentes, possam buscar o ponto de convergência, o consenso" (p. 179), afinal, para Viana, cada pessoa constrói seu mundo a sua maneira e por isso a escuta e o acolhimento é indispensável. Esse princípio resgata o caráter humano do processo, abrindo espaço para afetividade em sala de aula. Superando o caráter técnico e distante da avaliação mais tradicional, baseada em números, classificação e verificação. Viana, assim, ressalta que "essa perspectiva de avaliação tem, nesse princípio, o resgate da essência da avaliação, que é cuidar do processo de ensino e aprendizagem, sentar ao lado e acolher o outro" (p. 180). 


\section{Princípio da Confiança.}

Esse princípio dialoga com o princípio do Acolhimento e é essencial para superar o ritual de barganha que ocorre no espaço educativo. Segundo Viana (2014) esse ritual se dá quando "o professor ensina e o estudante aprende, depois professor avalia e o estudante devolve para o professor o que ele ensinou" (p. 180). O processo educativo passa a ser apenas uma prestação de contas, em que o professor escolhe a moeda e os estudantes que conseguem pagar estão "livres" de títulos de promissórias, diferente daqueles que não conseguem. Estes sofrem com os juros da dívida. Por isso a importância do princípio da Confiança, pois, assim como o princípio do Acolhimento, também "resgata o caráter humano da avaliação e tem como base as relações afetivas" (p. 180), na medida em que supera a tensão histórica do processo avaliativo, quando constrói pontes de humanidade entre professor e estudantes, afinal, o processo educativo é essencialmente formativo, como formar um estudante sem que haja confiança mútua? O estudante precisa confiar que o professor quer o seu bem, quer o seu crescimento e respeita o seu limite. Da mesma forma, o professor precisa confiar que não é preciso barganha para que os estudantes estudam e participem de suas aulas. Professor e estudantes precisam confiar um no outro.

\section{Princípio da Proatividade.}

A postura proativa é o motor para que haja negociação, acolhimento e confiança. Sem ela os acordos ficarão prejudicados, pois tanto o professor, quanto os estudantes precisam ter disponibilidade para o "novo". Viana ressalta que a avaliação não é um processo estativo e é no princípio da Proatividade que se encontro a base para esse dinamismo, tanto das decisões, como das reorientações. De acordo com Viana (2014, p. 180), “os acordos realizados no início do processo, não precisam ser considerados intocáveis. Podem ser refeitos, rediscutidos, revisitados sempre que necessário". Afinal, nem tudo o que se decide no início do processo pode ser mantido até o final. Portanto, mantendo-se uma base norteadora coerente dos acordos iniciais, eles devem ser reorientados caso não estejam mais respondendo as expectativas do grupo.

\section{Princípio Crítico-Reflexivo.}

Dialogando com o princípio da Proatividade, o princípio Crítico-Reflexivo é necessário para que as práticas avaliativas que, historicamente, primam pela padronização, memorização e reprodução de conteúdo sejam superadas. Para Viana, o estudante precisa ser entendido e formado como um ser ativo, pensando e construtor do conhecimento. As práticas inovadoras tanto de ensino, quanto de avaliação só podem ser efetivadas a partir de reflexões críticas, por isso o professor que 
vivencia a Avaliação da Experiência precisa propor instrumentos avaliativos que desafiem os estudantes, que os faça refletir, rever seus conceitos e que aguce a sua criatividade e desejo de aprender e de ir além cada vez mais. É preciso fugir de provas que têm como único objetivo a padronização do conhecimento, em que, as duras penas o estudante precisa "matar" o ser ativo e pensante que há dentro de si e se tornar apenas mais do mesmo.

\section{Princípio da Emancipação}

Um estudante que é formado dessa maneira, que é convidado a todo momento a pensar e a se colocar diante do conhecimento estará trilhando o caminho para a autonomia e emancipação. Viana (2014) defende o Princípio da Emancipação porque reconhece que a Avaliação da Experiência é, “antes de tudo, político-social, pois busca formar indivíduos, além de críticos, reflexivos, também emancipados, autônomos. Por esse motivo, não dialoga com vertentes que entendem o processo educativo de subordinação, passividade e dependência" (182). E quando fala de dependência se refere a realidade das escolas em que os estudantes passam os anos dependendo do professor para conhecer. Apenas os professores escolhem os assuntos a serem tratados em sala de aula. Os estudantes “aprenderam" a esperar e aceitar as decisões do professor. A formação de um estudante crítico, reflexivo, autônomo, emancipado requer do professor uma atitude acolhedora, negociadora, dentro de um processo de ensino e avaliação estimulante e bem planejado, mas com a escuta apurada para que também garanta a flexibilidade e a busca por consensos. Por isso Viana (2014) afirma que todos esses princípios dialogam e não existe um princípio mais importante do que o outro, eles se complementam.

\section{Princípio do Compartilhamento}

Essa complementação dos princípios se dá através do movimento de colaboração e por isso Viana propõe o princípio do Compartilhamento, que engloba mais do que a interação, pois pressupõe a ideia de colaboração e troca. Dessa forma, mais que interagir, as responsabilidades, sentimentos e ideias são compartilhados por todos. E ainda afirma que "em momentos de negociação, de troca, de partilhamentos, é comum que ocorram crises, cansaços, desgastes e insatisfações" (VIANA, 2014, p. 182), diante disso, a Avaliação da Experiência tem como alicerce os seus princípios que resgatam o caráter humano na avaliação. O compartilhamento supera tomadas de decisões unilaterais, responsabilidade de fracasso ou sucesso de apenas um dos lados, afinal, o processo educativo não tem apenas um sujeito e todo movimento que ocorre em sala de aula é a força resultante de diversas forças da coletividade. 


\section{Princípio Ético}

Diante do caráter humano que a Avaliação da Experiência apresenta, não poderia faltar o princípio Ético, que "é pano de fundo de todas as relações estabelecidas na Avaliação da Experiência e é essencial nos momentos de negociação, decisões, reencaminhamentos e compartilhamentos de responsabilidades" (p. 183). Para Viana (2014), para que a avaliação seja justa e coerente, e que possam ser primadas as relações de confiança entre professor e estudantes, a ética é de suma importância. Uma avaliação é ética quando tem como base critérios claros e acordados a partir de processo de negociação. Uma avaliação ética ocorre quando seus resultados não perseguem, não punem e não prejudicam os envolvidos (professor e estudantes). É ética quando auxilia na formação e no crescimento do grupo, quando considera as diferenças, as histórias individuais, os ritmos e as formas de aprender de cada um e quando, antes de tudo, considera que "todos têm direito de aprender" (p. 183).

Dessa forma, destaca-se o fato de que é possível perceber o quanto a Avaliação da Experiência coloca em "cheque" as práticas tradicionais da avaliação, pois tem em seu DNA o respeito à individualidade, o acolhimento do outro, a busca por compartilhamento de saberes e de responsabilidades, tendo como base práticas pedagógicas mais justas, a partir de sujeitos ativos, autônimos, que por meio do diálogo, vivenciam estratégias de ensino, aprendizagem e avaliação consensuais.

\section{Metodologia}

A proposta aqui apresentada foi elaborada pela pesquisadora e professora Viana e tem como aporte teórico da Avaliação da Experiência (VIANA, 2014). Todas as ações serão baseadas nos seus pressupostos e princípios. As ações contemplarão aspectos da pesquisa, do ensino e da extensão. Os estudos se darão a partir do Grupo de Estudos e Pesquisas em Ensino de Ciências - GEPEC e as ações serão no âmbito do Programa Internacional Despertando Vocações para Licenciaturas - PDVL. Essa proposta se dará em edição piloto no ano de 2016 e contará com extensionistas e estudantes de iniciação científica para a realização das ações.

\section{Resultados e Discussão}

Como o Laboratório de Avaliação se configura como uma proposta, neste espaço, ainda não será apresentado resultados. Ao invés disso, apresentaremos a proposta.

A proposta aqui desenhada por Viana apresenta três eixos de ação: ensino, pesquisa e extensão. 
Abaixo, elencaremos as principais ações de cada eixo.

\section{Ensino:}

Estudos sistemáticos acerca do aporte teórico da Avaliação da Experiência;

$>$ Formação de Grupos de Estudos por área de atuação - ENEM, Experimentos, Jogos Didáticos;

$>$ Preparação de materiais por GT;

$>$ Formação de estudantes na área de Avaliação.

\section{Pesquisa:}

$>$ Pesquisa sobre o campo da avaliação, seus limites e possibilidades;

$>$ Identificação de principais dificuldades dos estudantes;

$>$ Estudos sobre os principais obstáculos epistemológicos dos conteúdos que apresentam maiores dificuldades;

$>$ Pesquisa sobre as relações existentes entre as principais dificuldades e o distanciamento dos estudantes da área.

\section{Extensão:}

Elaboração de instrumentos avaliativos de acordo com as áreas - Jogos Didáticos, ENEM e Experimentos;

> Testagem de práticas avaliativas qualitativas e quantitativas, a partir de controle de variáveis;

$>$ Formação de Professores de acordos com as propostas elaboradas e testadas;

Será organizada uma sala com Vídeo e que comporte o desenvolvimento das ações desenvolvidas no âmbito do PDVL. Essas ações, antes de serem realizadas com a comunidade externa, serão avaliadas pelo grupo da avaliação dentro do Laboratório de Avaliação. Todas as ações serão filmadas e analisadas, para que sejam verificadas as necessidades de instrumentos avaliativos diagnósticos, de mediação (HOFFMANN, 2001), de regulação (SILVA, 2004), de emancipação (SAUL,2000), de reflexão, além dos momentos de debates, os momentos de negociações e de autoavaliação. Todas as propostas seguirão o percurso metodológico da Avaliação da Experiência, tendo como fio condutor seus pressupostos e princípios.

\section{Conclusões}


Após o exposto, espera-se que os resultados do Laboratório de Avaliação propostos possam contribuir significativamente para a materialização das práticas inovadoras da avaliação. Espera-se que seja possível superar o distanciamento tão frequentemente entre a literatura, os discursos, as concepções e as práticas avaliativas.

Por se configurar como uma proposta, muito ainda precisará ser realizado, muitos desafios superados, afinal, avaliação é um campo que pouco se discute, considerando que apesar da literatura publicada, a sua discussão em cursos de formação é muito limitada. Assim, será preciso estudos sistemáticos para formar pessoas que possam se debruçar acerca dessa proposta.

\section{Referências}

GUBA, E. G.; LINCOLN, Y. S. Fourth generation evaluation. Newbury Park, London, New Delhi: Sage, 1989.

HOFFMANN, J. Avaliação mediadora: uma prática em construção da pré-escola à universidade. Porto Alegre: Mediação, 2001.

KELLY, G. A. A theory of personality: the psychology of personal constructs. New York: W.W. Norton, 1963.

LIMA, K. S. Compreendendo as concepções de avaliação de professores de física através da teoria dos construtos pessoais. Recife, 2008. 163 p. Dissertação (Ensino das Ciências). Departamento de Educação, UFRPE, 2008.

SALES, E. S.; MONTEIRO, I. G. S.; LIMA, K. S. Formação de professor, diretrizes da Educação brasileira para o ensino de Química e Avaliação: saberes docentes essenciais à formação docente. In: VII Colóquio Internacional Educação e Contemporaneidade, 2013, São Cristóvão - SE. Anais do Colóquio Internacional Educação e Contemporaneidade, 2013.

SAUL, A. M. Avaliação emancipatória: desafio à teoria e à prática de Avaliação e reformulação de currículo. 5 ed. São Paulo: Cortez, 2000.

SILVA, J. F. Avaliação na perspectiva Formativa-Reguladora: Pressupostos Teóricos e Práticos. Porto Alegre: Mediação, 2004.

VIANA, K. S. L. Avaliação da Experiência: uma perspectiva de Avaliação para o ensino das Ciências da Natureza. 2014. 212f. Tese (Doutorado em Ensino de Física e Química) - Universidade Federal Rural de Pernambuco - UFRPE, Recife, 2014. 